\title{
HUBUNGAN KEIKUTSERTAAN PADA BPJS DENGAN KEPUASAN MENDAPATKAN PELAYANAN KESEHATAN
}

\author{
THE RELATIONSHIP BETWEEN PARTICIPATION IN THE BPJS WITH SATISFACTION OF \\ GETTING HEALTH SERVICES
}

\section{Derry Trisna Wahyuni S}

Akademi Analis Kesehatan Putra Jaya Batam, Komplek Tiban Mas Asri, Jl. Gajah Mada, Patam Lestari, Kec. Sekupang, Kota Batam, Kepulauan Riau 29426

Email :trisna_derry@yahoo.com

\begin{abstract}
Regulation of the Laws No.40 / 2004 on National Social Guarantees System, mandates that the compulsory social Guarantees to the entire population through a Social Guarantees Administrator (BPJS). Technical Assistance Research Program (TARP) in Washington in 2006 get a 96\% dissatisfied customers switch to competitors' services. Penumping PHC Survey of 2006 on satisfaction showed that ,49\% of patients are quite satisfied (Lupiyoadi \& Hamdani, 2006). Preliminary survey conducted in casa medical clinic on 10 patients obtained, 7 people have BPJS cards and 6 people satisfied with health services. The aim of research to determine the relationship of public participation in BPJS satisfaction level of health services. This research is quantitative with cross sectional approach, collecting data by distributing questionnaires and samples is Total Sampling. The study was conducted from April to July 2015 with 108 respondents, analyzed using Chi-Square. The results showed that respondents have BPJS cards as much as 78 or ( $72 \%$ ) and the level of satisfaction of health services that is satisfied by 99 respondents ( $92 \%)$. Of Chi - Square test with a limit of significance $(a)=0.05$, there is a relationship between participation in BPJS with satisfaction off getting health services. Expected to the peoples, who do not administer health insurance to take care of immediate switchover in (BPJS). The entire health personel in order to maintain and improve its performance, which is already well as the discipline of service time. For further research can add the total of respondents and took a new research and focus on a different assessment .
\end{abstract}

\section{Keywords : Participation In BPJS; Service Quality; Satisfaction}

\begin{abstract}
ABSTRAK
Undang-Undang No.40/2004 tentang Sistem Jaminan Sosial Nasional (SJSN) mengamanatkan bahwa jaminan sosial wajib bagi seluruh penduduk melalui suatu Badan Penyelenggara Jaminan Sosial (BPJS). Penelitian ini bersifat kuantitatif dengan pendekatan Cross Sectional, pengumpulan data dengan membagikan kuisioner dan dengan sampel Total Sampling. Penelitian dilakukan bulan April-Juli 2015 dengan 108 responden, analisis data menggunakan analisis Chi-Square. Hasil penelitian menunjukkan responden ikut serta pada BPJS sebanyak 78 orang atau (72\%) dan kepuasan mendapatkan pelayanan kesehatan yaitu puas sebanyak 99 responden (92\%). Dari uji Chi-Square dengan batas kemaknaan (a) $=0,05$, maka ada hubungan antara keikutsertaan pada BPJS dengan kepuasan mendapatkan pelayanan kesehatan. Diharapkan masyarakat yang belum mengurus pengalihan jaminan kesehatan untuk segera mengurus peralihannya pada (BPJS). Bagi peneliti selanjutnya dapat menambahkan jumlah responden dan mengambil tempat penelitian baru dan fokus pada penilaian yang berbeda.
\end{abstract}

Kata Kunci

: Keikutsertaan pada BPJS; Kepuasan 


\section{PENDAHULUAN}

Kesehatan adalah aspek yang sangat penting dalam kehidupan manusia. Setiap orang melakukan berbagai cara untuk memperoleh kesehatan yang prima. Seseorang yang menderita sakit akan berusaha untuk mengatasi dan mengobati penyakit yang dideritanya hingga sembuh. Terwujudnya keadaan sehat adalah kehendak semua pihak, untuk itu peranan penyelenggara pelayanan kesehatan seperti rumah sakit, puskesmas, klinik dan balai pengobatan lainnya adalah hal yang sangat penting (10).

Pemerintah bertanggung jawab atas upaya untuk meningkatkan derajat kesehatan, salah satunya dengan pelaksanaan jaminan kesehatan masyarakat melalui Jaminan Kesehatan Nasional (JKN) bagi kesehatan perorangan. Usaha ke arah itu telah dirintis pemerintah dengan menyelenggarakan beberapa bentuk jaminan sosial di bidang kesehatan, diantaranya adalah melalui PT Askes (Persero) dan PT Jamsostek (Persero) yang melayani antara lain pegawai negeri sipil, penerima pensiun, veteran, dan pegawai swasta, untuk masyarakat miskin dan tidak mampu, pemerintah memberikan jaminan melalui skema Jaminan Kesehatan Masyarakat (Jamkesmas) dan Jaminan Kesehatan Daerah (Jamkesda). Biaya kesehatan dan mutu pelayanan menjadi sulit terkendali, untuk mengatasi hal itu, pada tahun 2004, dikeluarkan UU No.40 tentang Sistem Jaminan Sosial Nasional (SJSN), UU 40/2004 ini mengamanatkan bahwa jaminan sosial wajib bagi seluruh penduduk termasuk JKN melalui suatu Badan Penyelenggara Jaminan Sosial (11) .

Pelayanan jasa kesehatan yang diberikan klinik kepada pasien dapat mengakibatkan banyak kerugian bagi pasien maupun klinik itu sendiri. Survey membuktikan bahwa tidak setiap konsumen yang kecewa dengan pelayanan menyampaikan keluhannya. Temuan yang di dapatkan Technical Assistance Research Program (TARP) di Washington mendapati kenyataan bahwa 96\% konsumen tidak puas (12). Tapi mempunyai jaminan kesehatan mempunyai manfaat yaitu pelayanan pencegahan dan pengobatan termasuk pelayanan obat dan bahan medis habis pakai sesuai dengan kebutuhan medis, selain itu BPJS sangat membantu masyarakat yang tidak mampu dalam mendapatkan pelayanan kesehatan dan memudahkan masyarakat peserta
BPJS diseluruh wilayah Indonesia karena berlaku secara nasional (12).

Selain itu hasil survey yang dilakukan Puskesmas Penumping Surakarta pada awal Tahun 2006 tentang kepuasan pasien di puskesmas menunjukan hasil bahwa 3\% pasien menyatakan tidak puas, $21 \%$ pasien menyatakan kurang puas, $49 \%$ pasien menyatakan cukup puas, dan $17 \%$ pasien menyatakan puas, dari pelayanan yang diberikan oleh Puskesmas Penumping Surakarta, dari hasil survey itu diketahui bahwa ada ketidak puasan yang muncul pada pasien di Puskesmas Penumping yang disebabkan oleh beberapa aspek yang belum memuaskan bagi pasien. Konsumen yang kecewa bisa menceritakan pelayanan yang diterima pada orang lain, menurut penelitian, mereka yang kecewa akan bercerita paling sedikit kepada 15 orang lainnya dengan asumsi 100 pasien yang kecewa, akan menyebar ke 37.500 orang lainnya (12). Berdasarkan hal tersebut, maka sangat diperlukan adanya upaya peningkatan kesadaran akan pentingnya membangun sistem manajemen pelayanan dan kualitas pelayanan kesehatan yang berfokus pada kepuasan pasien (12). Tujuan Penelitian ini adalah untuk mengetahui hubungan keikutsertaan pada BPJS dengan kepuasan mendapatkan pelayanan kesehatan di Klinik Umum Casa Medical Bengkong Kota Batam Tahun 2015

\section{BAHAN DAN METODE}

Penelitian ini bersifat kuantitatif dengan pendekatan Cross Sectional menggunakan data primer dengan cara membagikan angket. Pengambilan sampel menggunakan Total Sampling dilakukan bulan April-Juli 2015 dengan 108 responden dan data diolah menggunakan SPSS. Klinik Casa Medical adalah Klinik yang memiliki jaringan cukup banyak hampir seluruh wilayah Kota Batam seperti di wilayah padat penduduk di Kecamatan Bengkong dan memiliki rata-rata kunjungan pasien perhari yaitu lebih kurang 100 pasien perharinya

\section{HASIL DAN PEMBAHASAN}

\section{Analisa Univariat}

Tabel 1 Distribusi Frekuensi RespondenBerdasarkan Jenis Kelamin, Keikutsertaan pada BPJS padaKlinik Umum Casa Medical Bengkong Kota Batam Tahun 2015 


\begin{tabular}{lcc}
\hline \multicolumn{1}{c}{ Variabel } & n & \% \\
\hline $\begin{array}{l}\text { JenisKelamin } \\
\text { Laki-laki } \\
\text { Perempuan }\end{array}$ & 43 & 24 \\
Keikutsertaan Pada BPJS & 65 & 76 \\
$\begin{array}{l}\text { Tidak Memiliki } \\
\text { Memiliki }\end{array}$ & 30 & \\
Kepuasan Mendapatkan & 78 & 28 \\
$\begin{array}{l}\text { Pelayanan Kesehatan } \\
\text { Kurang Puas }\end{array}$ & & 72 \\
Puas & 9 & \\
\hline Jumlah & 99 & 8 \\
\hline
\end{tabular}

Dari hasil penelitian table 1 , didapat hasil sebanyak 43 responden ( $24 \%$ ) berjenis kelamin lakilaki dan yang berjenis perempuan sebanyak 65 responden ( $76 \%$ ). Sedangkan variable keikutsertaan pada BPJS banyak 30 responden (28\%) tidak memiliki Kartu BPJS, dan yang mempunyai kartu BPJS sebanyak 78 responden (72\%).Pada variable kepuasan mendapatkan pelayanan kesehatan, kategori kurang puas mendapatkan pelayanan kesehatan sebanyak 9 responden (8\%), dan sebagian besar responden mendapatkan kepuasan dalam pelayanan kesehatan sebanyak 99 responden (92\%).

\section{Analisa Bivariat}

Tabel 2 Hubungan Keikutsertaan Pada BPJS dengan Kepuasan Mendapatkan Pelayanan Kesehatan di Klinik Umum Casa Medical Bengkong Kota Batam Tahun 2015

\begin{tabular}{|c|c|c|c|c|c|c|c|c|}
\hline \multirow{4}{*}{ No } & \multirow{4}{*}{$\begin{array}{l}\text { Variabel } \\
\text { Independen } \\
\begin{array}{c}\text { Keikutsertaan Pada } \\
\text { BPJS }\end{array}\end{array}$} & \multicolumn{4}{|c|}{ Variabel Dependen } & \multirow{3}{*}{ Jumlah } & \multirow{3}{*}{\multicolumn{2}{|c|}{ p-Value }} \\
\hline & & \multirow{2}{*}{\multicolumn{3}{|c|}{$\frac{\text { Kepu }}{\text { Kurang Puas }}$}} & \multirow[b]{2}{*}{ Puas } & & & \\
\hline & & & & & & & & \\
\hline & & $\mathbf{n}$ & $\%$ & $\mathbf{n}$ & $\%$ & n & $\%$ & \\
\hline 1 & Tidak Memiliki & 7 & 23,3 & 23 & 76,7 & 30 & 100 & \multirow{2}{*}{0,002} \\
\hline \multirow[t]{2}{*}{2} & Memiliki & 2 & 2,6 & 76 & 97,4 & 78 & 100 & \\
\hline & Jumlah & 9 & & 99 & 108 & & & \\
\hline
\end{tabular}

Dari hasil penelitian, sebanyak 30 responden yang tidak memiliki keanggotaan pada PBJS, 7 responden $(23,3 \%)$ kurang puas dan 23 responden $(76,7 \%)$ puas mendapatkan pelayanan kesehatan. Sedangkan dari 78 responden ikut kepersertaan pada BPJS, sebanyak 2 responden (2,6\%) kurang puas dan puas sebanyak 76 responden atau mendapatkan pelayanan kesehatan. Dari uji ChiSquare dengan batas kemaknaan $(\alpha)=0,05$ maka ada hubungan keikutsertaan pada BPJS dengan kepuasan mendapatkan pelayanan kesehatan

\section{PEMBAHASAN \\ Keikutsertaan Pada BPJS}

Berdasarkan hasil analisa dari tabel diketahui keikutsertaan responden pada BPJS di Klinik Umum Casa Medical Bengkong yaitu sebanyak 78 responden didapatkan memiliki kartu BPJS atau (72\%), berdasarkan dari penelitian dapat diketahui bahwa sebagian responden di Klinik
Umum Casa Medical Bengkong Batam telah memiliki kartu BPJS.

Hal ini sesuai dengan FAQ (Frequently Asked Questions) (20). Badan Penyelenggara Jaminan Sosial bertujuan untuk mewujudkan terselenggaranya pemberian jaminan terpenuhinya kebutuhan esensial setiap orang agar dapat hidup layak, demi terwujudnya kesejahteraan sosial bagi seluruh rakyat Indonesia, dan sesuai dengan prinsip Badan Penyelenggara Jaminan Sosial Kepesertaan bersifat wajib, prinsip kepesertaan bersifat wajib adalah prinsip yang mengharuskan seluruh penduduk menjadi peserta jaminan sosial, yang dilaksanakan secara bertahap.

Ini sesuai dengan hasil penelitian yang dilakukan pada tahun 2014, dimana hasil hasil penelitian diketahui keikutsertaan penggunaan BPJS sebanyak 94\% (5) , yakni sama -sama memiliki keikutsertaan yang presentasi tinggi. 
Berdasarkan data diatas bahwa responden di Klinik Umum Casa Medical Bengkong telah memiliki Kartu BPJS selain itu peneliti juga menanyakan beberapa pertanyaan kepada responden yang berkaitan tentang penelitian. Hal ini disebabkan karena sebagian responden yang berkaitan dengan penelitian ini telah banyak mengikuti kegiatan penyuluhan atau penjelasan mengenai BPJS dan telah banyak mendapatkan informasi dari media massa dan elektronik.

\section{Kepuasan Mendapatkan Pelayanan Kesehatan}

Berdasarkan hasil penelitian yang dilakukan kepada semua responden sebanyak 108 responden menunjukkan kepuasan dalam mendapatkan pelayanan kesehatan sebagian besar responden merasakan puas yaitu sebanyak 99 responden (92\%) dari 108 responden hal ini sesuai dengan pelayanan yang diberikan tenaga kesehatan di Klinik Umum Casa Medical Bengkong.

Hal ini sesuai dengan teori J. Supranto, 2001 menyatakan, kepuasan konsumen adalah tingkat perasaan seseorang setelah membandingkan kinerja atau hasil yang dirasakannya dengan harapannya dan juga mengatakan Kepuasan konsumen berhubungan dengan pelayanan atau mutu produk yang ditawarkan kepada mereka

Hal ini sesuai dengan hasil penelitian dengan judul Hubungan Antara Persepsi Mutu Pelayanan Asuhan Keperawatan Dengan Kepuasan Pasien Rawat Inap Kelas III di RSUD Wangaya Kota Denpasar. Berdasarkan hasil penelitian dapat diamati bahwa kepuasan pasien pada penelitian ini sebagian besar responden menyatakan dalam kategori puas sebesar 61 orang (55\%) (1).

Hasil penelitian yang penulis lakukan, responden dengan kategori puas sebanyak $92 \%$ mendapatkan pelayanan kesehatan yang diberikan tenaga kesehatan yang berada di Klinik Casa Medical Bengkong. Reponden sebagian besar puas dengan pelayanan tenaga kesehatan seperti memberikan perhatian secara khusus kepada setiap pasien, pelayanan yang sopan dan ramah, perhatian terhadap keluhan pasien dan keluarganya , prosedur pelayanan tidak berbelit-belit, petugas memberikan informasi yang jelas mudah dimengerti, kebersihan, kerapian dan kenyamanan ruangan, keterampilan para dokter, perawat dan petugas lainnya dalam bekerja yang diberikan tenaga kesehatan yang ada di Klinik Casa Medical Bengkong Kota Batam.

\section{Hubungan Keikutsertaan pada BPJS dengan Kepuasan Mendapatkan Pelayanan Kesehatan}

Berdasarkan hasil penelitian, sebanyak 30 responden yang tidak memiliki keanggotaan pada PBJS, 7 responden $(23,3 \%)$ kurang puas dan 23 responden $(76,7 \%)$ puas mendapatkan pelayanan kesehatan. Sedangkan dari 78 responden ikut kepersertaan pada BPJS, sebanyak 2 responden $(2,6 \%)$ kurang puas dan puas sebanyak 76 responden atau $(97,4 \%)$ mendapatkan pelayanan kesehatan. Dari uji Chi-Square dengan batas kemaknaan $(\alpha)=$ 0,05 maka ada hubungan keikutsertaan pada BPJS dengan kepuasan mendapatkan pelayanan kesehatan. Bila dilihat dari uji Chi-Square dengan batas kemaknaan $(\alpha)=0,05$ dan hasil p-Value 0,002 yang berarti $p$-Value $<(\alpha)$, maka ada hubungan antara keikutsertaan pada BPJS dengan kepuasaan mendapatkan pelayanan kesehatan.

Berdasarkan uraian diatas dengan demikian, peneliti menyimpulkan responden yang ikut serta pada BPJS dan yang belum memiliki sebagian besar merasa puas dengan pelayanan kesehatan yang responden dapatkan. Reponden yang belum memiliki kartu BPJS juga diharapkan agar segera mendaftarkan diri agar terdaftar pada Badan Penyelenggara Jaminan Sosial karena dengan menggunakan BPJS pasien tidak perlu ragu dengan jaminan keamanan pelayanan dan kepercayaan terhadap pelayanan karena pelayanan yang diberikan tenaga kesehatan akan sesuia dengan kebutuhan pasien hal ini sesuai dengan undangundang BPJS.

\section{KESIMPULAN DAN SARAN}

Keikutsertaan pada BPJS sebagian besar atau 78 responden (72\%) dari 108 responden sudah memiliki kartu BPJS.Kepuasan mendapatkan pelayanan kesehatan sebanyak 99 responden ( 92\%).Responden yang memiliki Kartu BPJS dengan Kepuasan Puas 76 responden $(97,4 \%)$. Hasil dari uji Chi-Square p-Value 0,002< 0,05 maka ada hubungan keikutsertaan pada BPJS dengan kepuasan mendapatkan pelayanan kesehatan pada Klinik Umum Casa Medical Bengkong Kota Batam Tahun 2015 


\section{UCAPAN TERIMAKASIH}

Penelitian ini dapat dilaksanakan dengan baik berkat bantuan dari berbagai pihak, untuk itu peneliti mengucapkan terimakasih kepada Klinik Umum Casa Medical Bengkong Kota Batam yang telah memberikan kerjasama yang baik dalam penelitian ini.

\section{DAFTAR PUSTAKA}

1 Ida Ayu Dwidyaniti Wira.. Hubungan antara persepsi mutu pelayanan asuhan keperawatan dengan kepuasan pasien rawat inap kelas III di Rsud Wangaya Kota Denpasar. Tesis; 2014

2 Kementrian kesehatan Republik Indonesia. BUKU SAKU FAO(Frequently Asked Questions)BPJS KESEHATAN. Jakarta : Kementrian RI; 2013.

3 Mardianto. Jaminan Kesehatan. Bandung : Nuansa Aulia. Mubarak, ikbal, wahid, SKM dan Chayatin, Nurul. 2009. Ilmu Kesehatan Masyarakat. Salemba Medika : Jakarta; 2013.

4 Notoatmodjo, Soekidjo. Metodologi Penelitian Kesehatan. Jakarta : Rineka Cipta; 2010.

5 Tami, Putri Andini. Hubungan pengetahuan kepala keluarga tentang badan penyelenggara jaminan sosial dengan keikutsertaan dalam Penggunaan Badan Penyelenggara Jaminan sosial dikelurahan belian tahun 2014. KTI; 2014

6 Rumengan, jemmy. Metode Penelitian Kesehatan. Bandung : Cipta Pustaka Media Perintis; 2008.

7 Rumengan Dkk. Analisis data kuantitatif untuk penelitian kesehatan keperawatan dan kebidanan. Batam; 2010.

8 Syarifudin B. Panduan TA Keperawatan dan Kebidanan dengan SPSS, Grafindo Litera Medika, Jakarta; 2009.

9 Sugiyono. Metodologi penelitian administrasi (Pendekatan kuantitatif, kualititatif, dan RED). Bandung: Alfabeta; 2010.

10 Depkes RI. Keputusan Mentri Kesehatan RI No: 900/MENKES/VII/2007. Konsep Asuhan Kebidanan. Jakarta; 2007

11 Peraturan Presiden Republik Indonesia Nomor 12 Tahun 2013 Tentang Jaminan Kesehatan

12 Lupiyoadi dan Hamdani. Manajemen Pemasaran jasa Edisi kedua. Penerbit Salemba Empat: Jakarta; 2006

13 Kementerian Kesehatan RI. BPJS Kesehatan Buku saku FAQ (Frequently Asked Questions) Cetakan Pertama, Maret. Jakarta; 2013. 